Author affiliations and support information (if applicable) appear at the end of this article.

Published at jco.org on May 14, 2018.

Corresponding author: Li Wang, BMed, Msc, PhD, Department of Anesthesia, Michael G. DeGroote School of Medicine, McMaster University, MDCL 2112, 1280 Main St West, Hamilton, ON L8S 4K1, Canada; e-mail: wangli1@mcmaster.ca.

(C) 2018 by American Society of Clinical Oncology

$0732-183 X / 18 / 3618 w-1868 w / \$ 20.00$

\title{
Predictors of Unemployment After Breast Cancer Surgery: A Systematic Review and Meta-Analysis of Observational Studies
}

Li Wang, Brian Y. Hong, Sean A. Kennedy, Yaping Chang, Chris J. Hong, Samantha Craigie, Henry Y. Kwon, Beatriz Romerosa, Rachel J. Couban, Susan Reid, James S. Khan, Michael McGillion, Victoria Blinder, and Jason W. Busse

\section{$\begin{array}{llllllll}\text { A } & \text { B } & \text { S } & \text { T } & \text { R } & \text { A } & \text { C } & \text { T }\end{array}$}

\section{Purpose}

Breast cancer surgery is associated with unemployment. Identifying high-risk patients could help inform strategies to promote return to work. We systematically reviewed observational studies to explore factors associated with unemployment after breast cancer surgery.

\section{Methods}

We searched MEDLINE, EMBASE, CINAHL, and PsycINFO to identify studies that explored risk factors for unemployment after breast cancer surgery. When possible, we pooled estimates of association for all independent variables reported by more than one study.

\section{Results}

Twenty-six studies (46,927 patients) reported the association of 127 variables with unemployment after breast cancer surgery. Access to universal health care was associated with higher rates of unemployment (26.6\% $v 15.4 \%$; test of interaction $P=.05)$. High-quality evidence showed that unemployment after breast cancer surgery was associated with high psychological job demands (odds ratio [OR], 4.26; 95\% Cl, 2.27 to 7.97), childlessness (OR, 1.30; 95\% Cl, 1.11 to 1.53), lower education level (OR, 1.15; 95\% Cl, 1.05 to 1.25), lower income level (OR, 1.46; 95\% Cl, 1.24 to 1.73), cancer stage II, III or IV (OR, 1.43; $95 \% \mathrm{Cl}, 1.13$ to 1.82), and mastectomy versus breast-conserving surgery $(\mathrm{OR}, 1.18 ; 95 \% \mathrm{Cl}, 1.07$ to 1.30$)$. Moderate-quality evidence suggested an association with high physical job demands (OR, 2.11; $95 \% \mathrm{Cl}, 1.52$ to 2.93), African-American ethnicity (OR, 1.89; $95 \% \mathrm{Cl}, 1.21$ to 2.96 ), and receipt of chemotherapy (OR, 1.95; $95 \% \mathrm{Cl}, 1.36$ to 2.79). High-quality evidence demonstrated no significant association with part-time hours, blue-collar work, tumor size, positive lymph nodes, or receipt of radiotherapy or endocrine therapy; moderate-quality evidence suggested no association with age, marital status, or axillary lymph node dissection.

\section{Conclusion}

Addressing high physical and psychological job demands may be important in reducing unemployment after breast cancer surgery.

\section{J Clin Oncol 36:1868-1879. (C) 2018 by American Society of Clinical Oncology}

\section{INTRODUCTION}

Breast cancer is the most common cancer among women and is diagnosed most often in workingage adults. Ten-year survival rates have improved markedly, particularly in developed countries (eg, $86 \%$ in the United States in $2017,{ }^{1} 78 \%$ in the United Kingdom in 2010 to $2011^{2}$ ); however, cancer survivorship is associated with unemployment. ${ }^{3}$ Rates of return to work within 1 year of diagnosis range from $43 \%$ to $93 \%,{ }^{4}$ and a meta-analysis found that breast cancer survivors were more likely to be unemployed compared with healthy control participants $(35.6 \% v 31.7 \%$; pooled relative risk [RR], 1.28; 95\% CI, 1.11 to 1.49$).^{3}$ Indirect costs, including sick leave and disability benefits, constitute $70 \%$ of the total costs associated with breast cancer. $^{5}$

Unemployment among breast cancer survivors is associated with reduced quality of life ${ }^{6-8}$ and increased mortality, ${ }^{8-10}$ whereas resuming employment is associated with better social functioning, greater financial security, improved health, and higher self-esteem. ${ }^{4,11-18}$ Knowledge of risk factors for unemployment could help inform optimal 
treatment to facilitate return to work; however, previous systematic reviews of factors associated with unemployment after breast cancer surgery have several limitations, including outdated searches, inadequate risk of bias assessment, lack of statistical pooling of measures of association, and failure to evaluate the quality of evidence. ${ }^{4,11,19-21}$ To address these limitations, we conducted a systematic review and meta-analysis of observational studies to identify risk factors for employment status after breast cancer surgery.

\section{METHODS}

We completed our systematic review in accordance with the reporting of the Meta-analysis Of Observational Studies in Epidemiology (MOOSE) statement ${ }^{22}$ and registered our protocol with PROSPERO (CRD42014013338). Before performing our analysis, we included an additional subgroup analysis to explore whether lack of availability of universal health care was associated with lower rates of unemployment after breast cancer surgery. Specifically, the United States does not provide universal health care, and most working-age Americans receive health insurance coverage through their employer. ${ }^{23}$ Maintaining health insurance may provide a powerful incentive to return to work. We also conducted a post hoc subgroup analysis to explore whether a higher proportion of patients employed at baseline was associated with lower unemployment after breast cancer surgery.

\section{Data Sources and Searches}

We searched MEDLINE, EMBASE, CINAHL, and PsycINFO from inception to March 1, 2017, without language restrictions. An experienced academic librarian developed search strategies for each electronic database (Data Supplement). We screened the reference lists of all eligible studies and 11 previous reviews $3,4,7,10,11,19-21,24-26$ for additional studies.

We included cohort or case-control studies that used an adjusted analysis to explore risk factors for unemployment after breast cancer surgery. We included both direct (eg, not returning to work, not working, unemployment) and indirect (eg, sick leave, unemployment benefits, disability pension, loss of work productivity) measures of unemployment. We excluded conference abstracts. Studies were ineligible if they included, in all available models, significant associations with variables collected after baseline; in such instances, the status of the predictor may be a result rather than a cause of employment status. When study populations overlapped by $>50 \%$ among articles, we included only the study with the largest sample size and longest follow-up. Studies excluded for population overlap or significant factors collected after baseline are listed in the Data Supplement.

\section{Study Selection}

Paired reviewers independently screened the titles and abstracts of identified citations and full texts of potentially eligible studies. Reviewers resolved any disagreements by discussion or with the help of an adjudicator. We used online systematic review software (DistillerSR, Evidence Partners, Ottawa, Canada) to facilitate literature screening.

\section{Quality Assessment and Data Extraction}

Using standardized, pilot-tested data extraction forms and a detailed instruction manual, pairs of reviewers extracted data from all eligible studies, independently and in duplicate. We used the following four criteria from the Users' Guides to the Medical Literature ${ }^{27}$ to assess the risk of bias: (1) representativeness of the study population; (2) validity of outcome assessment; (3) loss to follow-up ( $\geq 20 \%$ was considered a high risk of bias); and (4) whether predictive models were adjusted for age, severity of breast cancer, adjuvant therapy, and work-related factors. We also explored whether factors included in the final models were data driven (only those significant in bivariable analysis, and thus more vulnerable to chance) or theory driven. We used predefined criteria to select one model for data extraction if a study reported multiple regression models (Data Supplement). Two reviewers, blinded to results, independently categorized dependent variables as direct or indirect measures of unemployment and as high or low thresholds for resuming employment.

\section{Data Synthesis and Analysis}

We used the kappa statistic ( $\kappa)$ to measure inter-rater agreement of full-text screening. ${ }^{28}$ We pooled the prevalence of unemployment among eligible studies using random-effects models after performing a FreemanTukey double arcsine transformation to stabilize the variance. ${ }^{29}$ When possible, we pooled all factors associated with employment status that were reported by more than one study and presented odds ratios (ORs) and associated 95\% CIs. When studies provided the measure of association as a relative risk (RR) or hazard ratio, we converted them to an OR if the baseline risk (ie, the proportion of patients in the reference or unexposed group who were unemployed at follow-up) was available. ${ }^{30,31}$ We considered ethnicity to be a social construct and did not collapse categories such as African American, Black African, and Black Caribbean into a single group. $^{32}$

We calculated a single OR for converting categorical variables to continuous variables (eg, age) using methods described in the Data Supplement. For studies that reported separate RR estimates for subgroups (eg, income quartiles), we pooled related associations using the inverse variance method to generate an overall measure of association. ${ }^{33}$ We used random-effects models for all meta-analyses. We explored the consistency of association between our pooled results and studies reporting the same predictors that were not possible to pool. We used the following three criteria to identify predictors that were not amenable to pooling and showed promise for future research: (1) a statistically significant association with unemployment of $P \leq .01,(2)$ a large magnitude of association $(\mathrm{OR} \geq 2.0)$; and (3) a sample size $\geq 500 .^{34}$

To avoid overestimating the strength of association, we used an OR of 1 for predictors that were tested in bivariable analyses but were excluded from adjusted analyses because of nonsignificance or were included in multivariable analyses with the only information provided that they were not significant. We imputed an associated variance for all such predictors using the hot deck approach. ${ }^{35}$ To facilitate interpretation, we calculated the absolute risk increase (ARI) for each predictor amenable to metaanalysis. We estimated the baseline risk for unemployment (10\% in the low-risk group, who reported the highest quartile income) using data from the study eligible for review with the largest sample size among studies at low risk of bias. ${ }^{36}$ We used Stata statistical software version 15 (StataCorp, College Station, TX) for all statistical analyses. All comparisons were two tailed, with a threshold $P$ of .05 .

\section{Publication Bias}

We explored for publication bias by visual assessment of asymmetry of the funnel plot for each pooled predictor and calculation of Begg's rank correlation test, ${ }^{37}$ when there were at least 10 studies in a meta-analysis. ${ }^{33,38}$

\section{Subgroup Analyses, Metaregression, and Sensitivity Analyses}

We evaluated heterogeneity for all pooled estimates through visual inspection of forest plots, ${ }^{38}$ because statistical tests of heterogeneity can be misleading when sample sizes are large and associated measures of precision are therefore narrow. ${ }^{39}$

We generated four a priori hypotheses to explain variability among studies, assuming a larger association with unemployment and (1) a shorter duration of follow-up, (2) a direct measure of unemployment, (3) a lower threshold for employment, and (4) a greater risk of bias on a criteria-by-criteria basis. We conducted subgroup analyses only if each subgroup contained two or more studies. We performed sensitivity 
analyses to examine the effect of imputing data for nonsignificant postulated predictors, of converting categorical data for age to continuous data, and of different cutoffs for a higher versus a lower level of education.

\section{Quality of Evidence}

We used the Grading of Recommendations Assessment, Development and Evaluation (GRADE) approach to summarize the quality of evidence for all meta-analyses as high, moderate, low, or very low. ${ }^{38}$ Given a $10 \%$ baseline risk of unemployment after breast cancer surgery, ${ }^{36}$ we estimated that a $5 \%$ increase in absolute risk would likely be sufficient to address modifiable risk factors, which can be directly targeted in an effort to reduce unemployment. We further estimated that an absolute increase in risk of $10 \%$ for a nonmodifiable factor would be sufficient to identify high-risk candidates for intervention. Therefore, we rated down for imprecision if the $95 \% \mathrm{CI}$ associated with the ARI included $5 \%$ for modifiable risk factors or $10 \%$ for nonmodifiable risk factors.

\section{RESULTS}

We identified 20,770 unique records, of which we retrieved 179 articles in full text; 26 cohort studies proved eligible (Fig 1). There was near perfect agreement $(\kappa=0.83)$ among reviewers at the fulltext review stage. We successfully contacted three of nine authors to confirm eligibility ${ }^{40}$ or to verify data. ${ }^{41,42}$

Among our 26 eligible studies, nine were conducted in the United States, ${ }^{43-51} 14$ in Europe (including Sweden, ${ }^{41,52-56}$ the Netherlands, ${ }^{57,58}$ Denmark, ${ }^{36,59}$ France, ${ }^{12}$ Germany, ${ }^{42}$ Norway, ${ }^{60}$ and the United Kingdom ${ }^{61}$ ), two in South Korea, ${ }^{62,63}$ and one in Canada. ${ }^{64}$ The median sample size was 337 (interquartile range, 149-1,220), and the median duration of follow-up was 30 months (interquartile range, 12-46 months). Most studies (58\% [15 of 26]) reported that all patients were employed at baseline, ${ }^{12,36,41,43-47,49,50,53,54,57,61,64}$ four studies reported that $>75 \%$ but $<100 \%$ were employed at baseline, ${ }^{48,52,56,60}$ and five studies ${ }^{42,58,59,62,63}$ reported employment rates ranging from $40.3 \%$ to $69.2 \%$ at baseline; two studies ${ }^{51,55}$ did not report the rate of employment at baseline. Eleven studies (42\%) used indirect measures of unemployment, ${ }^{36,47,49,51,52,54-56,58-60}$ and five studies (19\%) used a high threshold for resuming employment (eg, working to the same extent as before the breast cancer, working full time ${ }^{46,53,55,57,64}$; Data Supplement).

\section{Risk of Bias}

Reporting of methodologic safeguards against risk of bias was limited among eligible studies, with 77\% (20 of 26) not meeting at least one of our risk of bias items ${ }^{12,41,42,45-49,52,54-64}$ (Data Supplement). Fourteen studies (54\%) either failed to report loss to follow-up ${ }^{46,58,63}$ or reported $\geq 20 \%$ loss to followup. ${ }^{42,47,48,50,54-57,61,62,64}$ Only nine studies (35\%) reported adequately adjusted regression models. ${ }^{36,43,44,48-51,53,64}$ Seven studies $(27 \%)$ only included variables significant in bivariable analysis in their final regression model, ${ }^{45,48,49,53,56,62,64}$ and 16 studies $(62 \%)$ failed to present data for nonsignificant predictors in their adjusted analysis ${ }^{12,41,43,45,47,49,51,53,54,56,57,59-62,64}$ (Data Supplement). We detected no evidence of publication bias (Table 1; Data Supplement).

\section{Prevalence of Unemployment}

Twenty-five studies ${ }^{12,36,41-63}$ reported prevalence of unemployment after breast surgery, which ranged from $5.6 \%$ to $56.3 \%$. Only access to universal health care explained betweenstudy heterogeneity, suggesting that patients in the United States were less likely to be unemployed $(15.4 \%$; $95 \% \mathrm{CI}, 10.0 \%$ to

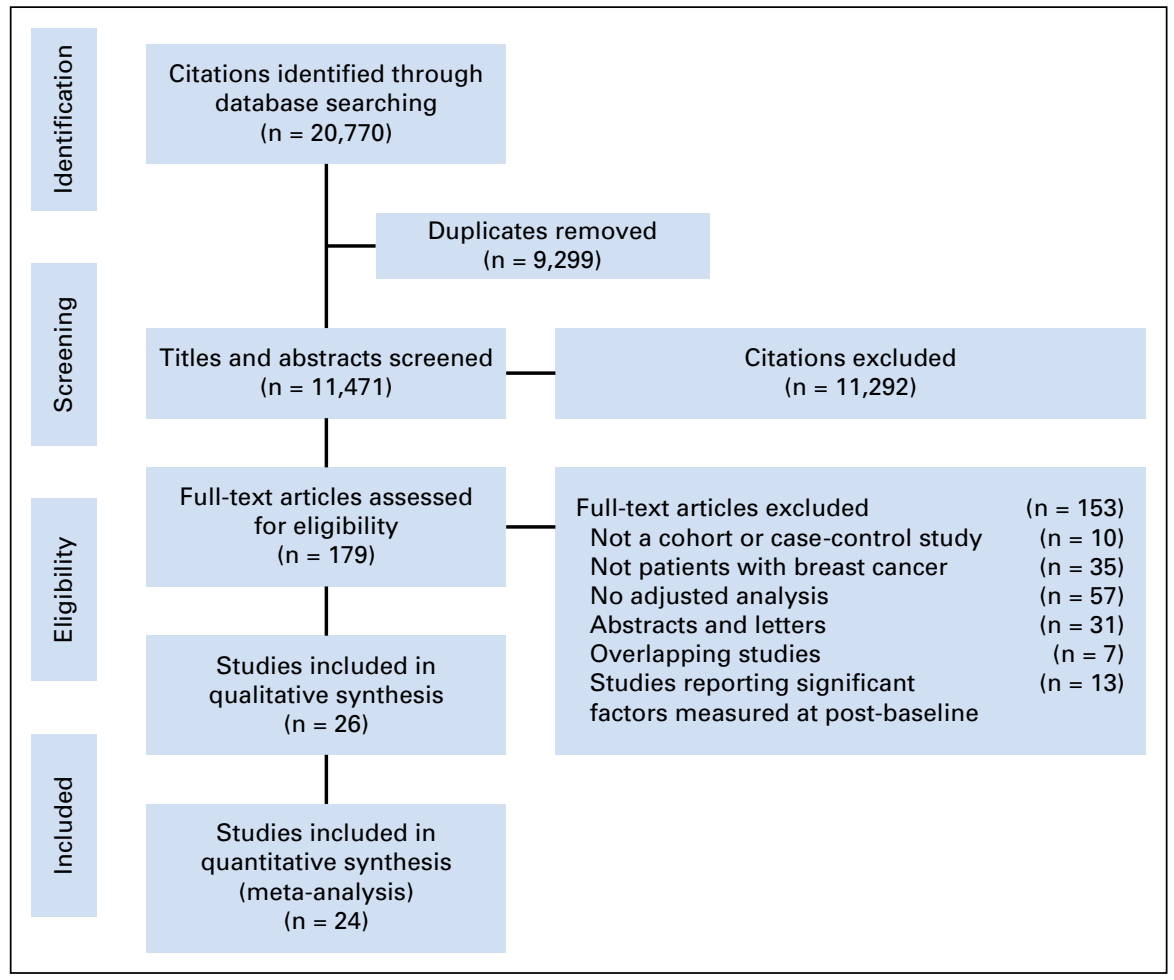

Fig 1. Flow diagram of study selection. 


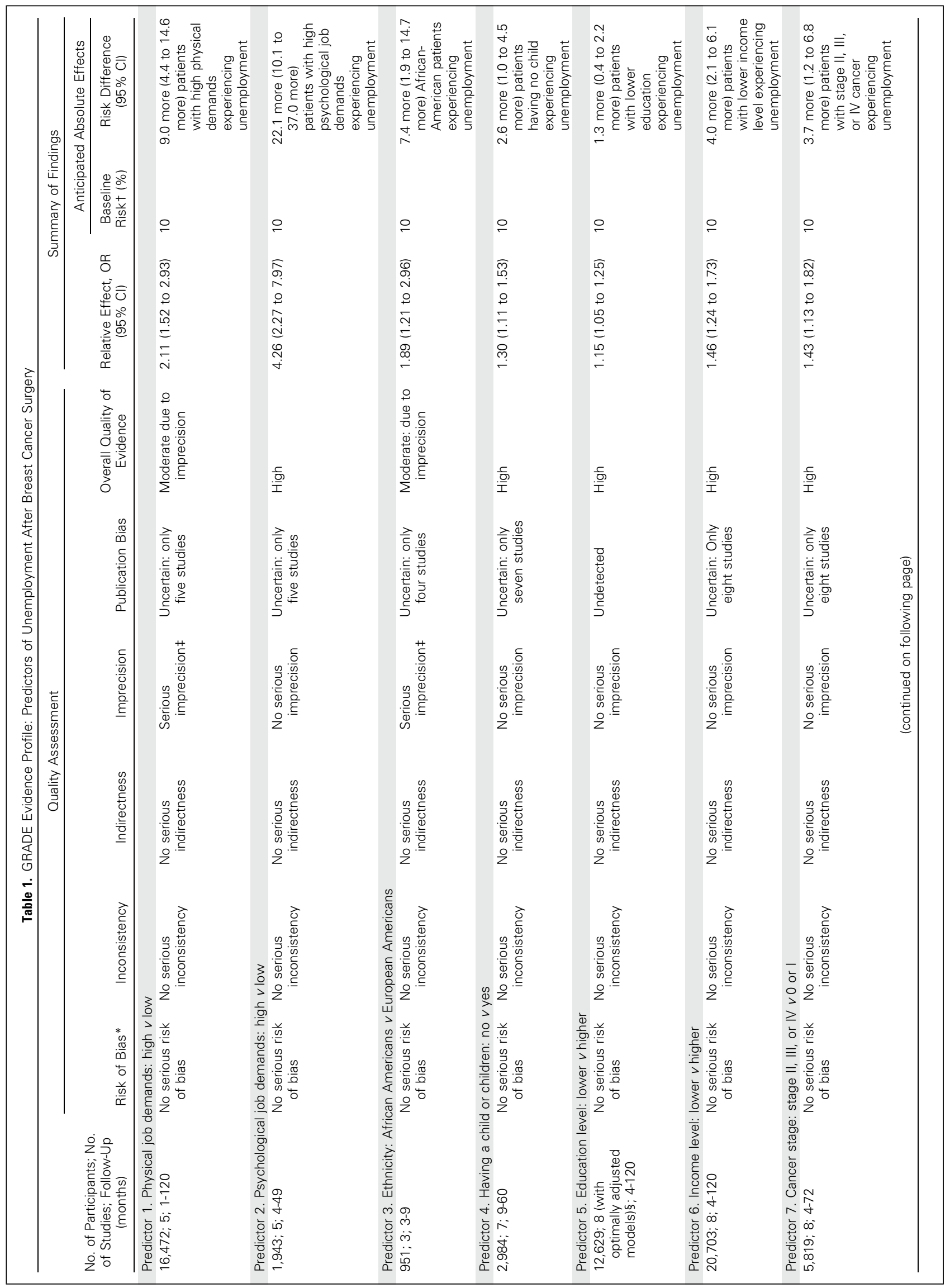




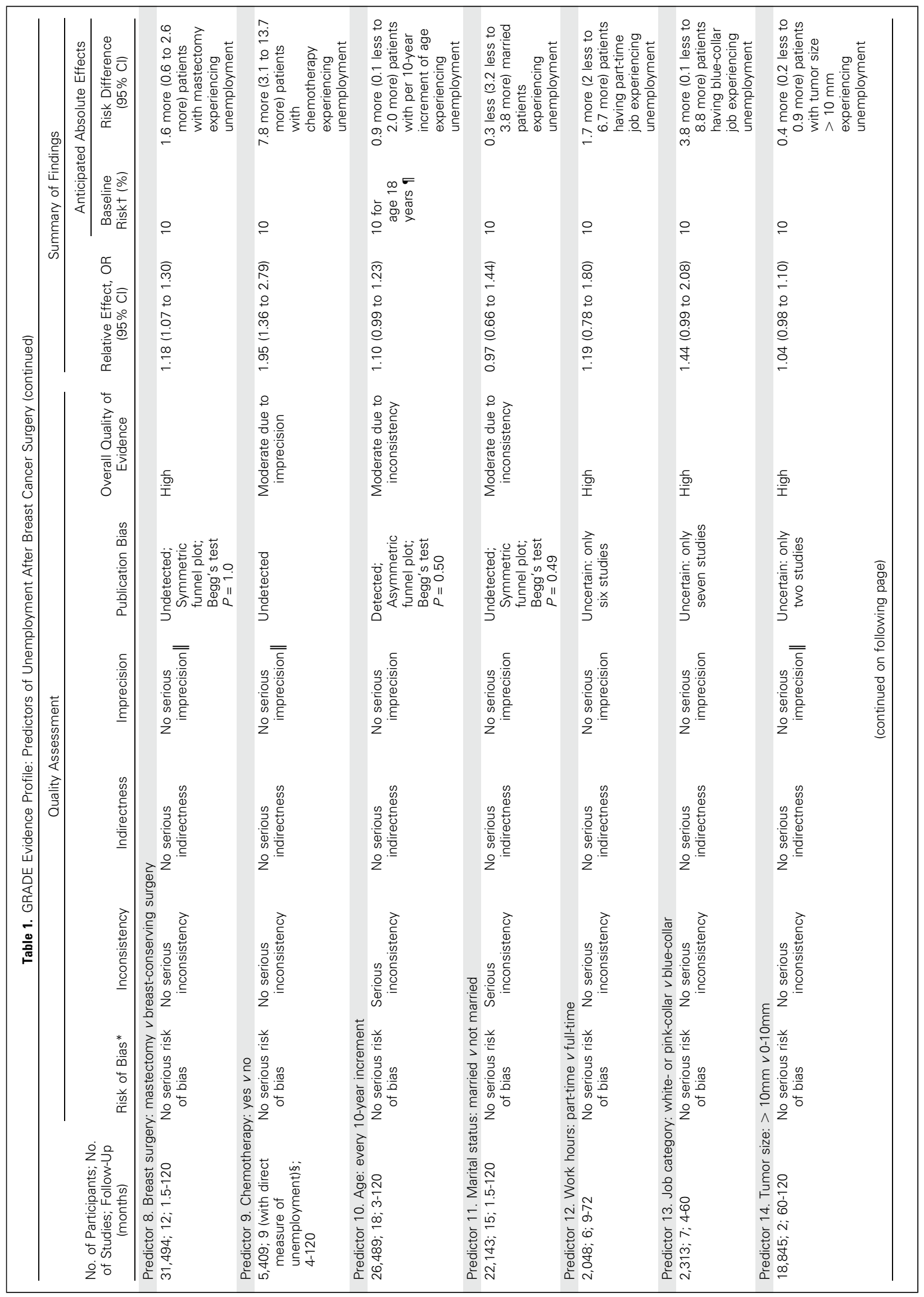




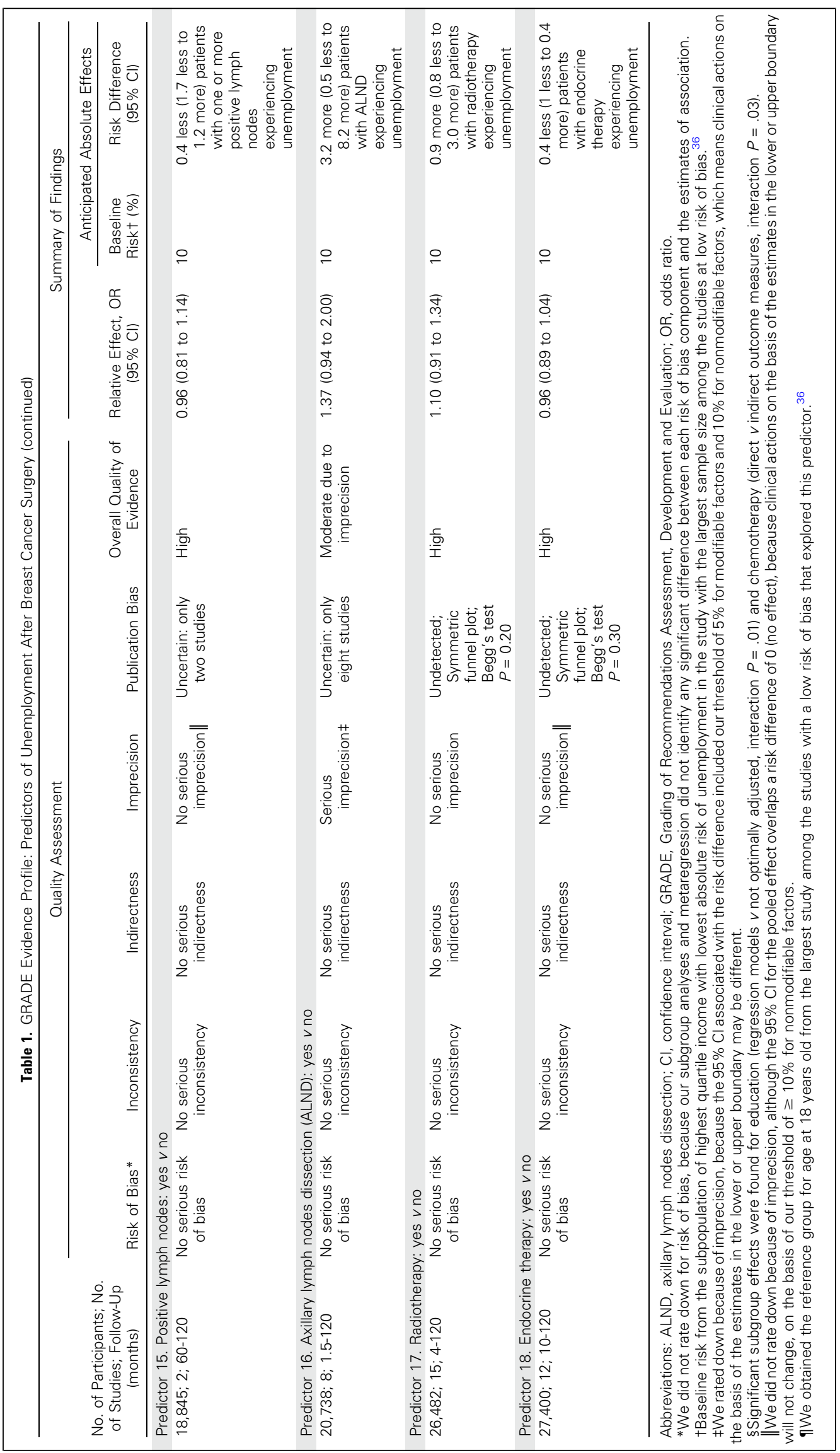


21.6\%) compared with patients from countries with universal health care $(26.6 \% ; 95 \% \mathrm{CI}, 20.0 \%$ to $33.9 \% ; P=.05$ for the interaction; Data Supplement) No significant subgroup effects were detected for direct versus indirect measures of unemployment, high versus low threshold for return to work, and risk of bias (interaction $P$ values ranged from 0.35 to 0.89 ), or metaregression for unemployment and duration of follow-up $(P=.62)$ or proportion of patients employed at baseline $(P=.31)$.

\section{Predictors of Unemployment}

Twenty-six studies involving 46,927 patients reported the association of 127 independent variables with unemployment after breast cancer surgery, 18 of which were suitable for meta-analysis on the basis of our criteria.

Work-related factors. We found a significant association between two modifiable factors and unemployment after breast cancer surgery: high psychological job demands (OR, 4.26 [95\% CI, 2.27 to 7.97]; high-quality evidence; Fig 2A; ARI, 22.1\% [95\% CI, $10.1 \%$ to $37.0 \%]$ ) and high physical job demands (OR, 2.11 [95\% CI, 1.52 to 2.93]; moderate-quality evidence; Fig 2B; ARI, 9.0\% [95\% CI, $4.4 \%$ to $14.6 \%$ ]; Table 1). Psychological job factors included job strain (low job decision control and high psychological job demands $)^{53}$; perceived psychological or organizational constraints at work ${ }^{12}$; and employment support or accommodation in flexible work schedule, paid leave, and/or modifications of job

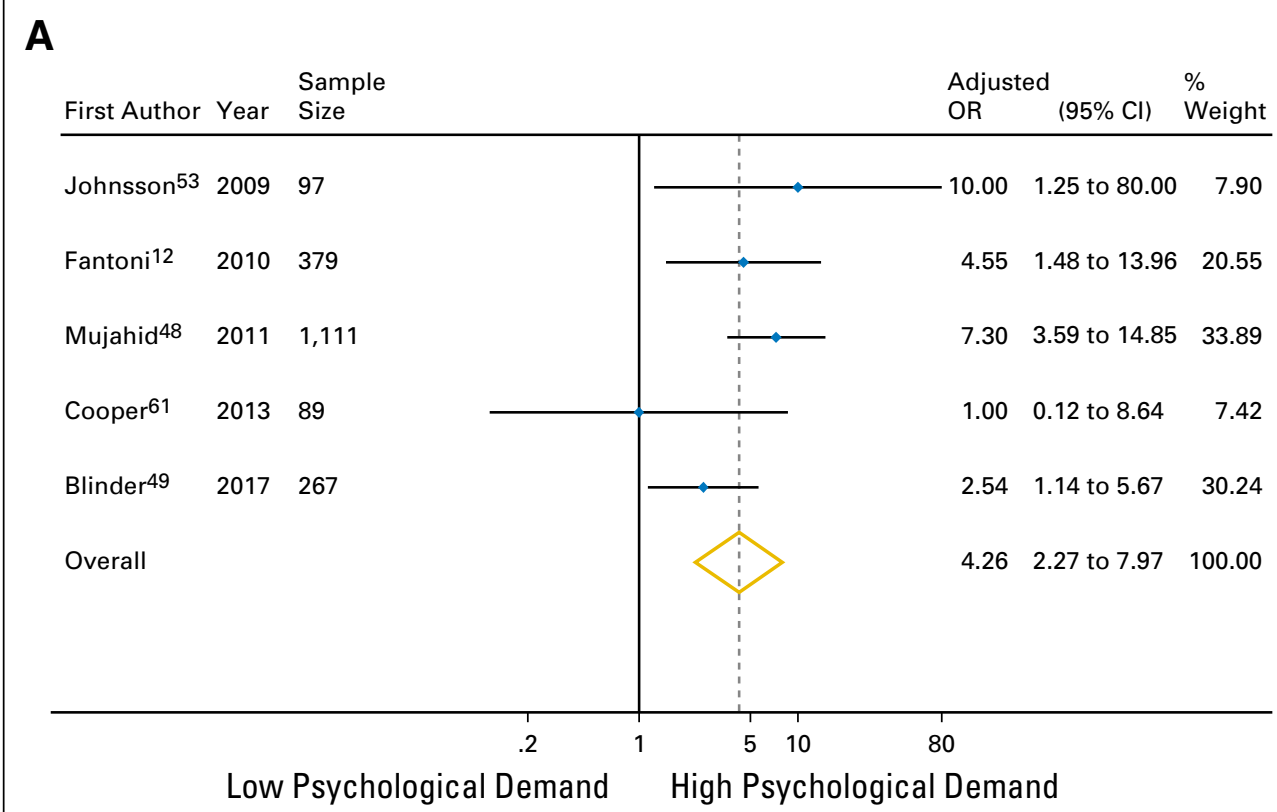

B

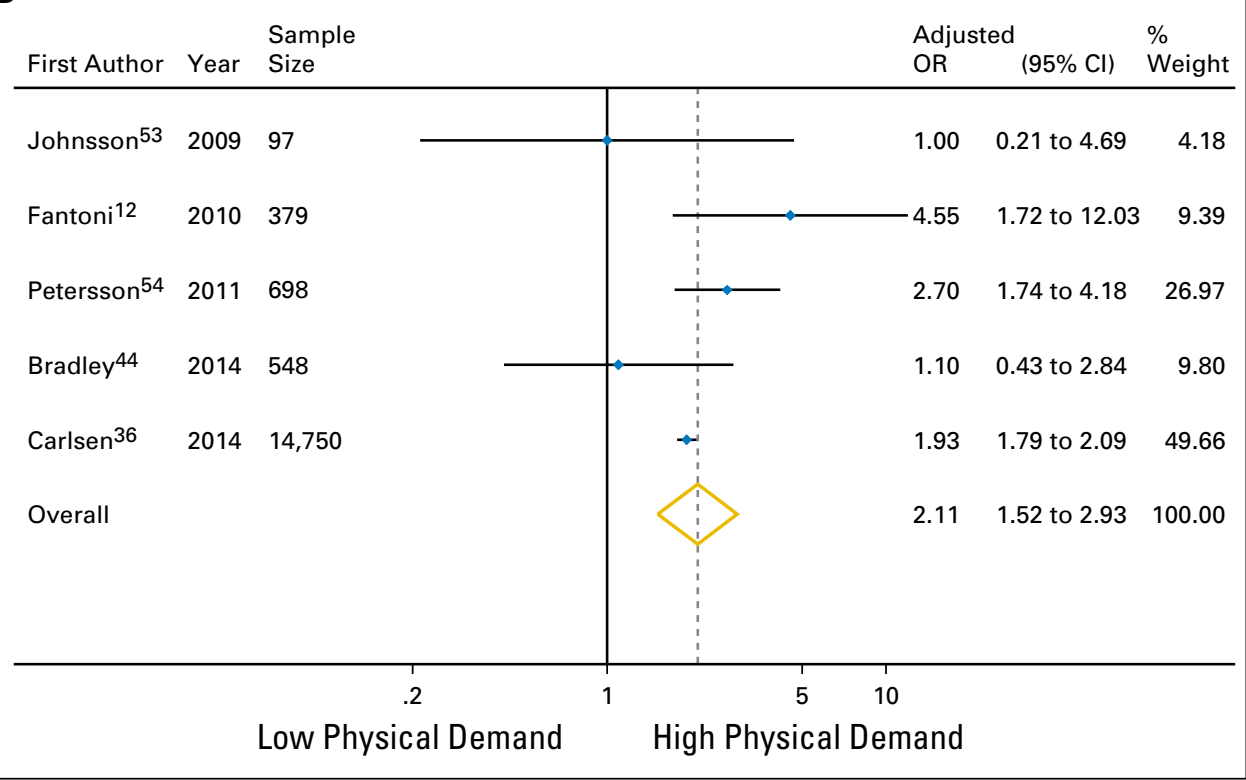

Fig 2. Meta-analysis of the association of significant predictors for unemployment. (A) Psychological job demands (high $v$ low). (B) Physical job demands (high $v$ low). (C) Chemotherapy (yes $v$ no; interaction $P=.03)$. OR, odds ratio. Note that weights are from random-effects analysis. 


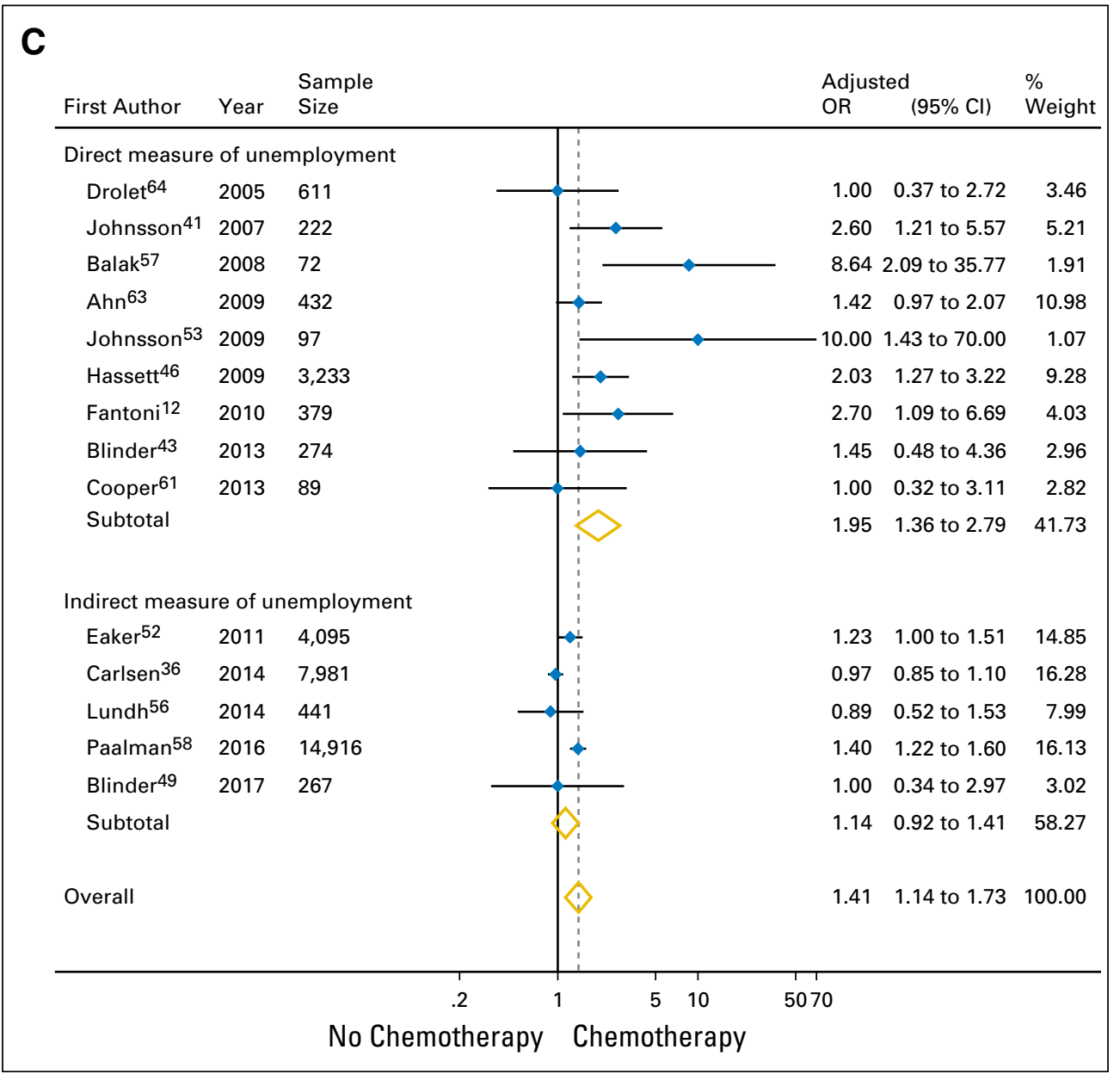

tasks. ${ }^{48,49,61}$ Definitions of high physical job demands included manual work, ${ }^{36,53}$ strenuous work postures, ${ }^{54}$ and physically demanding jobs. ${ }^{12,44}$

We considered job type (blue collar $v$ pink or white collar) and work hours (part time $v$ full time) as nonmodifiable factors, because they are rarely modified in practice. High-quality evidence suggested no significant association between unemployment and blue-collar versus white- or pink-collar work (OR, 1.44; 95\% CI, 0.99 to 2.08; Data Supplement) or part-time employment (OR, 1.19; $95 \%$ CI, 0.78 to 1.80; Data Supplement; Table 1).

Sociodemographic factors. We found high-quality evidence for a significant association between unemployment and childlessness (OR, 1.30 [95\% CI, 1.11 to 1.53]; Data Supplement; ARI 2.6\% [95\% CI, $1.0 \%$ to $4.5 \%$ ]), lower education level (OR, 1.15 [95\% CI, 1.05 to 1.25]; Data Supplement; ARI, $1.3 \%$ [95\% CI, $0.4 \%$ to 2.2\%]), and lower income level (OR, 1.46 [95\% CI, 1.24 to 1.73 ]; Data Supplement; ARI, $4.0 \%$ [95\% CI, 2.1\% to $6.1 \%]$ ); and moderate-quality evidence for a significant association with African-American ethnicity (OR, 1.89 [95\% CI, 1.21 to 2.96]; Data Supplement; ARI, $7.4 \%$ [95\% CI, $1.9 \%$ to $14.7 \%$; Table 1$)$. Moderate-quality evidence showed no significant association between unemployment and age (OR for every 10-year increment, 1.10; 95\% CI, 0.99 to 1.23; Data Supplement) or marital status (OR for married $v$ not married, $0.97 ; 95 \% \mathrm{CI}, 0.66$ to 1.44 ; Data Supplement; Table 1).
Medical factors. We found high-quality evidence for a significant association between unemployment and cancer stage II, III, or IV versus 0 or I (OR, 1.43 [95\% CI, 1.13 to 1.82]; Data Supplement; ARI, 3.7\% [95\% CI, $1.2 \%$ to $6.8 \%$ ]) and mastectomy versus breast-conserving surgery (OR, 1.18 [95\% CI, 1.07 to 1.30]; Data Supplement; ARI, $1.6 \%$ [95\% CI, $0.6 \%$ to $2.6 \%]$ ); and moderate-quality evidence for an association with receipt of chemotherapy (OR, 1.95 [95\% CI, 1.36 to 2.79]; Fig 2C; ARI, 7.8\% [95\% CI, $3.1 \%$ to $13.7 \%$ ]; Table 1 ).

High-quality evidence showed no significant association between unemployment and tumor size (OR for $>10 \mathrm{~mm} v 0$ to $10 \mathrm{~mm}, 1.04$; 95\% CI, 0.98 to 1.10; Data Supplement), positive lymph nodes (OR, 0.96; 95\% CI, 0.81 to 1.14; Data Supplement), receipt of radiotherapy $(\mathrm{OR}, 1.10 ; 95 \% \mathrm{CI}, 0.91$ to 1.34 ; Data Supplement), or endocrine therapy (OR, 0.96; 95\% CI, 0.89 to 1.04; Data Supplement; Table 1). Moderate-quality evidence suggested no association between unemployment and axillary lymph node dissection (OR, 1.37; 95\% CI, 0.94 to 2.00; Data Supplement).

Factors not amenable to pooling. The Data Supplement presents the associations with unemployment for the 109 factors that were not amenable to meta-analysis. Seven of these predictors were consistently associated with unemployment: (1) sickness absence 1 year before breast cancer diagnosis, (2) paid disability 
leave, (3) physician-advised work absence, (4) no regular endurance exercise before diagnosis, (5) preferred provider organization or point of service with capitation versus basic or comprehensive health plan, (6) receipt of multimodal cancer therapy, and (7) baseline perception of lower control over effects of cancer at work (Data Supplement). Two of these factors (sickness absence 1 year before breast cancer diagnosis and physician-advised work absence) met our criteria as promising for future study. Ninety-five factors were consistently not associated with unemployment (Data Supplement), and seven factors (country of birth, place of residence, unemployment status before and at diagnosis, lymphedema, shoulder function impairment, fatigue, and quality of life-physical functioning after surgery) showed conflicting associations across studies (Data Supplement).

\section{Subgroup Analyses, Metaregression, and Sensitivity Analyses}

We found significant subgroup effects for the associations of receipt of chemotherapy (interaction $P=.03$ for direct $v$ indirect outcome measures; Table 1; Fig 2C) and low education level (interaction $P=.01$ for optimally adjusted models $v$ not optimally adjusted models; Table 1; Data Supplement) with unemployment, and presented results for direct outcome measures and optimally adjusted models, respectively (Table 1 ). No additional subgroup analysis or metaregression was significant (Data Supplement). Our sensitivity analyses found no important differences in results whether we incorporated missing data for nonsignificant predictors, used different cutoffs for high versus low education level, or included data for age that we converted from categorical to continuous data (Data Supplement).

\section{DISCUSSION}

Rates of unemployment after breast cancer surgery are variable and are significantly lower in the United States (15.4\%) than in countries with universal health care $(26.6 \%)$. We found highquality evidence that high psychological job demands; AfricanAmerican ethnicity; childlessness; lower education; lower income level; cancer stage II, III, or IV; and mastectomy are associated with unemployment after breast cancer surgery; and moderate-quality evidence for an association with high physical job demands and receipt of chemotherapy. The strongest of these associations were for high psychological job demands and high physical job demands, with an absolute increase in risk of unemployment of $22 \%$ and $9 \%$, respectively (Table 1 ). High-quality evidence demonstrated no significant association between part-time or full-time work, job category (blue $v$ white- or pink-collar job), tumor size, positive lymph nodes, receipt of radiotherapy, or endocrine therapy with unemployment; and moderate-quality evidence found no significant association for age, marital status or axillary lymph nodes dissection (Table 1). Investigators have tested 109 additional predictors that could not be statistically pooled (Data Supplement). Of these, sickness absence 1 year before diagnosis ${ }^{52}$ and physicianadvised work absence ${ }^{64}$ warrant additional study.

The strengths of our review include explicit eligibility criteria and a comprehensive search with no language restrictions that identified 16 cohort studies ${ }^{36,42-44,48-52,54-56,58,59,61,62}$ that were not included in previous systematic reviews. ${ }^{4,11,19-21}$ We used the GRADE approach to appraise the quality of evidence, imputed data for missing nonsignificant predictors to avoid overestimating associations, and conducted subgroup and sensitivity analysis that confirmed robust effects. We presented both relative risk increases and ARIs, which more clearly convey the importance of associations.

Limitations include the inability to pool data for predictors from studies that used different continuous outcome measures to assess unemployment in linear regression models, ${ }^{47,51}$ because the estimates of association are outcome specific. The results of these studies were generally consistent with the results of studies amenable to pooling (Data Supplement). We pooled measures of association reported at the longest follow-up time, which ranged from 1 to 120 months; however, metaregression found no systematic differences attributable to length of follow-up. The studies included in our meta-analyses used different outcome measures for unemployment (Data Supplement); however, we conducted subgroup analyses for direct versus indirect measures of unemployment and high versus low thresholds of return to work and restricted our findings to direct or high-threshold outcomes when significant interactions were identified. Use of employment measures endorsed by national statistical agencies, such as the United States Bureau of Labor Statistics ${ }^{65}$ and Statistics Canada, ${ }^{66}$ may prove helpful for both clinical practice and research purposes.

Previous systematic reviews ${ }^{4,11,19-21}$ have qualitatively summarized risk factors for unemployment after breast cancer surgery. We have confirmed and quantified these associations, which include African-American ethnicity, lower educational or income level, more advanced cancer, mastectomy, receipt of chemotherapy, and heavy physical work demands. We have also identified two additional predictors: childlessness and high psychological job demands. In addition, we found moderate- to high-quality evidence that age, marriage status, part-time work, job type, tumor size, positive lymph nodes, axillary lymph nodes dissection, receipt of radiotherapy, and endocrine therapy are not associated with unemployment, despite having been proposed as risk factors by three prior reviews. ${ }^{4,20,21}$

We found that breast cancer survivors residing in the United States are more likely to return to work, and this may be influenced by the American health care system. Specifically, the United States is the only developed country without universal health care, ${ }^{67}$ and most workers have access to health care insurance through their employers. $^{23}$ Even with insurance, the mean family health insurance premium (combining both employer and employee contributions) represented $33.9 \%$ of median US household income in $2015 .^{68}$ More than $60 \%$ of all personal bankruptcies in the United States are the result of medical expenses, ${ }^{69}$ and fear of losing health insurance has been shown to influence return to work after cancer treatment. ${ }^{46}$ What is not known is whether higher rates of employment in the United States after breast cancer surgery are sustained.

Our review identified two work-related factors (physical and psychological job demands) that showed associations with unemployment sufficiently large to suggest targeted interventions. A 2017 systematic review found that high-intensity exercise improved the ability to work after cancer treatment. ${ }^{70}$ A 2015 
Cochrane review found moderate-quality evidence that multidisciplinary interventions, involving physical, psychoeducational, and vocational components, improve the rate of return to work among patients with cancer. ${ }^{71}$ Furthermore, a 2017 scoping review found evidence to recommend the development of multicomponent interventions that include both the clinic and the workplace to meet the particular needs of patients with breast cancer. ${ }^{72}$ Our findings suggest that physicians should consider inquiring about high psychological and physical job demands among patients undergoing breast cancer surgery; however, the optimal means by which to capture this information is unclear. ${ }^{73}$ Future research should also explore whether screening for job demands leads to better patient outcomes.

Mastectomy, compared with breast-conserving surgery, was associated with a statistically significant, but modest, increase in unemployment after surgery. Mastectomy has also been associated with poor body image; reduced quality of life; and lower social functioning, role functioning, and physical functioning among patients with breast cancer. ${ }^{74-76}$ There was a significant decline in mastectomy rates from 2005 to $2010(P<.01)$ in Europe with a progressive reduction of $4.24 \%$ per year. ${ }^{77}$ In the United States, mastectomy rates increased from $34.3 \%$ in $1998 \%$ to $37.8 \%$ in 2011 among patients eligible for breast-conserving surgery (adjusted OR, $1.34 ; 95 \% \mathrm{CI}, 1.31$ to 1.38$).{ }^{78}$ Moreover, breastconserving surgery has shown similar long-term survival and equivalent recurrence rates compared with mastectomy in patients with early breast cancer ${ }^{79-86}$; however, mastectomy rates among patients with early breast cancer are considerably lower in Europe (25.1\%) than in the United States $(35.5 \%) .^{78,87}$ Our findings provide additional information helpful for shared decision making between surgeons and patients undergoing breast cancer surgery who are eligible for breast-conserving surgery.

We did not find any individual nonmodifiable risk factor, on the basis of our criteria, that would warrant targeting for intervention. However, a combination of risk factors, for instance, low income level and receipt of chemotherapy, might constitute a population warranting special attention. There is preliminary evidence that behavioral interventions and high-intensity exercise may decrease the length of absence from work among patients with cancer. ${ }^{20,70,88}$

Our review adds to a growing body of evidence suggesting that nonmedical factors may be more important than injury or disease burden in predicting return to function. ${ }^{89-92}$ Although highquality evidence supports a strong association between axillary lymph node dissection and the development of persistent pain after breast cancer surgery (ARI, 21\%; 95\% CI, $13 \%$ to $29 \%$ ), ${ }^{34}$ we found moderate-quality evidence for no significant association with axillary lymph node dissection and return to work. Our results suggest that rehabilitation programs that focus only on addressing medical issues and symptoms associated with breast cancer will be unlikely to improve return-to-work rates.

Unemployment after breast cancer surgery was associated with high psychological or physical job demands; AfricanAmerican ethnicity; childlessness; lower education; lower income level; cancer stage II, III, or IV; mastectomy; and receipt of chemotherapy. Observational studies are required to determine if lower rates of unemployment are sustained among patients with breast cancer in the United States. Future research should also establish the association between sickness absence before cancer diagnosis or physician-advised work absence and unemployment and determine whether interventions targeting high workplace demands can improve return-to-work rates after breast cancer surgery.

\section{AUTHORS' DISCLOSURES OF POTENTIAL CONFLICTS} OF INTEREST

Disclosures provided by the authors are available with this article at jco.org.

\section{AUTHOR CONTRIBUTIONS}

Conception and design: Li Wang, Jason W. Busse

Administrative support: Li Wang

Collection and assembly of data: Li Wang, Brian Y. Hong, Sean A.

Kennedy, Yaping Chang, Chris J. Hong, Samantha Craigie, Henry Y. Kwon, Beatriz Romerosa, Rachel J. Couban

Data analysis and interpretation: Li Wang, Susan Reid, James S. Khan, Michael McGillion, Victoria Blinder, Jason W. Busse

Manuscript writing: All authors

Final approval of manuscript: All authors

Accountable for all aspects of the work: All authors

\section{REFERENCES}

1. American Cancer Society: Breast cancer facts \& figures 2017-2018. https://www.cancer.org/content/ dam/cancer-org/research/cancer-facts-and-statistics/ breast-cancer-facts-and-figures/breast-cancer-factsand-figures-2017-2018.pdf

2. Cancer Research UK: Breast cancer survival statistics. http://www.cancerresearchuk.org/healthprofessional/cancer-statistics/statistics-by-cancer-type/ breast-cancer/survival\#heading-Zero

3. de Boer AG, Taskila T, Ojajärvi A, et al: Cancer survivors and unemployment: $A$ meta-analysis and meta-regression. JAMA 301:753-762, 2009

4. Islam T, Dahlui M, Majid HA, et al: Factors associated with return to work of breast cancer survivors: A systematic review. BMC Public Health 14:S8, 2014
5. Lidgren $M$, Wilking $N$, Jönsson $B$ : Cost of breast cancer in Sweden in 2002. Eur J Health Econ 8:5-15, 2007

6. Engel J, Kerr J, Schlesinger-Raab A, et al: Predictors of quality of life of breast cancer patients. Acta Oncol 42:710-718, 2003

7. Spelten ER, Sprangers MA, Verbeek JH: Factors reported to influence the return to work of cancer survivors: A literature review. Psychooncology 11:124-131, 2002

8. Timperi AW, Ergas IJ, Rehkopf $\mathrm{DH}$, et al: Employment status and quality of life in recently diagnosed breast cancer survivors. Psychooncology 22:1411-1420, 2013

9. Waxler-Morrison N, Hislop TG, Mears B, et al: Effects of social relationships on survival for women with breast cancer: A prospective study. Soc Sci Med 33:177-183, 1991

10. Mehnert A: Employment and work-related issues in cancer survivors. Crit Rev Oncol Hematol 77:109-130, 2011
11. Banning M: Employment and breast cancer: $A$ meta-ethnography. Eur J Cancer Care (Engl) 20: 708-719, 2011

12. Fantoni $S Q$, Peugniez $C$, Duhamel $A$, et al: Factors related to return to work by women with breast cancer in northern France. J Occup Rehabil 20:49-58, 2010

13. Feuerstein M, Todd BL, Moskowitz MC, et al: Work in cancer survivors: A model for practice and research. J Cancer Surviv 4:415-437, 2010

14. Hoving $\mathrm{JL}$, Broekhuizen $\mathrm{ML}$, Frings-Dresen $\mathrm{MH}$ : Return to work of breast cancer survivors: A systematic review of intervention studies. BMC Cancer 9:117, 2009

15. Johnsson $A$, Fornander $T$, Rutqvist LE, et al: Factors influencing return to work: A narrative study of women treated for breast cancer. Eur $\mathrm{J}$ Cancer Care (Engl) 19:317-323, 2010

16. Nachreiner NM, Dagher RK, McGovern PM, et al: Successful return to work for cancer survivors. AAOHN J 55:290-295, 2007 
17. Tamminga SJ, de Boer AG, Verbeek JH, et al: Return-to-work interventions integrated into cancer care: A systematic review. Occup Environ Med 67: 639-648, 2010

18. Rueda $S$, Chambers $L$, Wilson $M$, et al: Association of returning to work with better health in working-aged adults: A systematic review. Am J Public Health 102:541-556, 2012

19. Zomkowski K, Cruz de Souza B, Pinheiro da Silva $F$, et al: Physical symptoms and working performance in female breast cancer survivors: A systematic review. Disabil Rehabil 40:1485-1493, 2018

20. Park J, Shubair M: Returning to work after breast cancer: A critical review. Int J Disabil Manag 8:E1, 2013

21. Sun $Y$, Shigaki $C L$, Armer JM: Return to work among breast cancer survivors: A literature review. Support Care Cancer 25:709-718, 2017

22. Stroup DF, Berlin JA, Morton SC, et al: Metaanalysis of observational studies in epidemiology: A proposal for reporting. Meta-analysis Of Observational Studies in Epidemiology (MOOSE) group. JAMA 283:2008-2012, 2000

23. Congressional Budget Office: Federal subsidies for health insurance coverage for people under age 65: 2016 to 2026

24. van Muijen $P$, Weevers $N L$, Snels $\mid A$, et al: Predictors of return to work and employment in cancer survivors: A systematic review. Eur J Cancer Care (Engl) 22:144-160, 2013

25. Duijts SF, van Egmond MP, Spelten E, et al: Physical and psychosocial problems in cancer survivors beyond return to work: A systematic review. Psychooncology 23:481-492, 2014

26. Stergiou-Kita M, Grigorovich $A$, Tseung $V$, et al: Qualitative meta-synthesis of survivors' work experiences and the development of strategies to facilitate return to work. J Cancer Surviv 8:657-670, 2014

27. Randolph AG, Cook DJ, Guyatt, G: Chapter 20. Prognosis, in Guyatt G, Drummond R, Meade MO, et al (eds): Users' Guides to the Medical Literature: A Manual for Evidence-Based Clinical Practice (ed 3), JAMA evidence, 2015, pp 421-29

28. Landis JR, Koch GG: The measurement of observer agreement for categorical data. Biometrics 33:159-174, 1977

29. Freeman MF, Tukey JW: Transformations related to the angular and the square root. Ann Math Stat 21:607-611, 1950

30. Wang Z: Converting odds ratio to relative risk in cohort studies with partial data information. J Stat Softw 55:1-11, 2013

31. Grant RL: Converting an odds ratio to a range of plausible relative risks for better communication of research findings. BMJ 348:f7450, 2014

32. Yudell $M$, Roberts $D$, DeSalle $R$, et al: SClENCE AND SOCIETY. Taking race out of human genetics. Science 351:564-565, 2016

33. Higgins JPT, Green S: Cochrane handbook for systematic reviews of interventions version 5.1.0 [updated March 2011]. http://training.cochrane.org/ handbook

34. Wang L, Guyatt GH, Kennedy SA, et al: Predictors of persistent pain after breast cancer surgery: A systematic review and meta-analysis of observational studies. CMAJ 188:E352-E361, 2016

35. Gelman A, Hill J: Chapter 25. Missing-data imputation, in Gelman A, Hill J (eds): Data Analysis Using Regression and Multilevel/Hierarchical Models. New York, NY, Cambridge University Press, 2007, pp 529-44

36. Carlsen K, Ewertz M, Dalton SO, et al: Unemployment among breast cancer survivors. Scand J Public Health 42:319-328, 2014
37. Begg CB, Mazumdar M: Operating characteristics of a rank correlation test for publication bias. Biometrics 50:1088-1101, 1994

38. Iorio A, Spencer FA, Falavigna M, et al: Use of GRADE for assessment of evidence about prognosis: Rating confidence in estimates of event rates in broad categories of patients. BMJ 350:h870, 2015

39. Rücker G, Schwarzer G, Carpenter JR, et al: Undue reliance on $\mathrm{I}(2)$ in assessing heterogeneity may mislead. BMC Med Res Methodol 8:79, 2008

40. Bouknight RR, Bradley CJ, Luo Z: Correlates of return to work for breast cancer survivors. J Clin Oncol 24:345-353, 2006

41. Johnsson $A$, Fornander $T$, Olsson $M$, et al: Factors associated with return to work after breast cancer treatment. Acta Oncol 46:90-96, 2007

42. Noeres D, Park-Simon TW, Grabow J, et al: Return to work after treatment for primary breast cancer over a 6-year period: Results from a prospective study comparing patients with the general population. Support Care Cancer 21:1901-1909, 2013

43. Blinder V, Patil $S$, Eberle $C$, et al: Early pre dictors of not returning to work in low-income breas cancer survivors: A 5-year longitudinal study. Breast Cancer Res Treat 140:407-416, 2013

44. Bradley $\mathrm{CJ}$, Wilk A: Racial differences in quality of life and employment outcomes in insured women with breast cancer. J Cancer Surviv 8:49-59, 2014

45. Satariano WA, DeLorenze GN: The likelihood of returning to work after breast cancer. Public Health Rep 111:236-241, 1996

46. Hassett MJ, O'Malley AJ, Keating NL: Factors influencing changes in employment among women with newly diagnosed breast cancer. Cancer 115 2775-2782, 2009

47. Lavigne JE, Griggs JJ, Tu XM, et al: Hot flashes, fatigue, treatment exposures and work productivity in breast cancer survivors. J Cancer Surviv 2:296-302, 2008

48. Mujahid MS, Janz NK, Hawley ST, et al: Racial/ ethnic differences in job loss for women with breast cancer. J Cancer Surviv 5:102-111, 2011

49. Blinder V, Eberle C, Patil S, et al: Women with breast cancer who work for accommodating employers more likely to retain jobs after treatment. Health Aff (Millwood) 36:274-281, 2017

50. Bushunow PW, Sun $Y$, Raubertas RF, et al: Adjuvant chemotherapy does not affect employment in patients with early-stage breast cancer. J Gen Intern Med 10:73-76, 1995

51. Chapman SA: The experience of returning to work for employed young women with breast cancer. Ann Arbor: University of California, Berkeley. Diss Abstr Int B Sci Eng 62:193, 2000

52. Eaker S, Wigertz A, Lambert PC, et al: Breast cancer, sickness absence, income and marital status. A study on life situation 1 year prior diagnosis compared to 3 and 5 years after diagnosis. PLoS One 6:e18040, 2011

53. Johnsson $A$, Fornander $T$, Rutqvist $L E$, et al: Predictors of return to work ten months after primary breast cancer surgery. Acta Oncol 48:93-98, 2009

54. Petersson LM, Wennman-Larsen A, Nilsson $M$, et al: Work situation and sickness absence in the initial period after breast cancer surgery. Acta Oncol 50:282-288, 2011

55. Nilsson $H$, Angerås $U$, Bock $D$, et al: Is preoperative physical activity related to post-surgery recovery? A cohort study of patients with breast cancer. BMJ Open 6:e007997, 2016

56. Lundh MH, Lampic C, Nordin K, et al: Sickness absence and disability pension following breast cancer - A population-based matched cohort study. Breast 23:844-851, 2014

57. Balak F, Roelen CA, Koopmans PC, et al: Return to work after early-stage breast cancer: $A$ cohort study into the effects of treatment and cancerrelated symptoms. J Occup Rehabil 18:267-272, 2008

58. Paalman $\mathrm{CH}$, van Leeuwen $\mathrm{FE}$, Aaronson NK, et al: Employment and social benefits up to 10 years after breast cancer diagnosis: A population-based study. Br J Cancer 114:81-87, 2016

59. Peuckmann V, Ekholm O, Sjøgren $P$, et al: Health care utilisation and characteristics of longterm breast cancer survivors: Nationwide survey in Denmark. Eur J Cancer 45:625-633, 2009

60. Hauglann B, Benth JS, Fosså SD, et al: A cohort study of permanently reduced work ability in breast cancer patients. J Cancer Surviv 6:345-356, 2012

61. Cooper AF, Hankins M, Rixon L, et al: Distinct work-related, clinical and psychological factors predict return to work following treatment in four different cancer types. Psychooncology 22:659-667, 2013

62. Lee MK, Kang HS, Lee KS, et al: Three-year prospective cohort study of factors associated with return to work after breast cancer diagnosis. J Occup RehabilRehabil 27:547-558, 2017

63. Ahn E, Cho J, Shin DW, et al: Impact of breast cancer diagnosis and treatment on work-related life and factors affecting them. Breast Cancer Res Treat 116:609-616, 2009

64. Drolet M, Maunsell E, Mondor M, et al: Work absence after breast cancer diagnosis: A populationbased study. CMAJ 173:765-771, 2005

65. Bureau of Labor Statistics: How the government measures unemployment. https://www.bls. gov/cps/cps_htgm.htm

66. Statistics Canada: Guide to the labour force survey. http://www.statcan.gc.ca/pub/71-543-g/71543-g2017001-eng.htm?contentType=application \% 2Fpdf

67. Stuckler D, Feigl AB, Basu S, et al: The politica economy of universal health coverage (background paper for the symposium). Presented at the First Global Symposium on Health Systems Research, Montreaux, Switzerland, 16-19 November, 2010

68. Emanuel EJ, Glickman A, Johnson D: Measuring the burden of health care costs on US families: The Affordability Index. JAMA 318:1863-1864, 2017

69. Himmelstein DU, Thorne D, Warren E, et al: Medical bankruptcy in the United States, 2007: Results of a national study. Am J Med 122:741-746, 2009

70. Hunter EG, Gibson RW, Arbesman M, et al: Systematic Review of Occupational Therapy and Adult Cancer Rehabilitation: Part 2. Impact of Multidisciplinary Rehabilitation and Psychosocial, Sexuality, and Return-to-Work Interventions. Am J Occup Ther 71:7102100040p1-7102100040p8, 2017

71. de Boer A, Taskila TK, Tamminga SJ, et al: Interventions to enhance return to work for cancer patients: A cochrane review and meta-analysis. Psychooncology 24:258, 2015

72. Bilodeau K, Tremblay D, Durand MJ: Exploration of return-to-work interventions for breast cancer patients: A scoping review. Support Care Cancer 25:1993-2007, 2017

73. Shea $T$, De Cieri H: Workplace stress evaluation tools: A snapshot review. http://www.iscrr. com.au/_data/assets/pdf_file/0011/297758/WorkplaceStress-Evaluation-Tools_Full-Report_1011.pdf

74. Ahn SH, Park BW, Noh DY, et al: Healthrelated quality of life in disease-free survivors of 
breast cancer with the general population. Ann Oncol 18:173-182, 2007

75. Arndt V, Stegmaier C, Ziegler H, et al: Quality of life over 5 years in women with breast cancer after breast-conserving therapy versus mastectomy: A population-based study. J Cancer Res Clin Oncol 134:1311-1318, 2008

76. Engel J, Kerr J, Schlesinger-Raab A, et al: Quality of life following breast-conserving therapy or mastectomy: Results of a 5-year prospective study. Breast J 10:223-231, 2004

77. Garcia-Etienne CA, Tomatis M, Heil J, et al: Mastectomy trends for early-stage breast cancer: $A$ report from the EUSOMA multi-institutional European database. Eur J Cancer 48:1947-1956, 2012

78. Kummerow KL, Du L, Penson DF, et al: Nationwide trends in mastectomy for early-stage breast cancer. JAMA Surg 150:9-16, 2015

79. Johns N, Dixon JM: Should patients with early breast cancer still be offered the choice of breast conserving surgery or mastectomy? Eur J Surg Oncol 42:1636-1641, 2016

80. Early Breast Cancer Trialists' Collaborative Group: Effects of radiotherapy and surgery in early breast cancer. An overview of the randomized trials. N Engl J Med 333:1444-1455, 1995 [Erratum: N Engl J Med 334:1003, 1996]
81. Morris AD, Morris RD, Wilson JF, et al: Breastconserving therapy vs mastectomy in early-stage breast cancer: A meta-analysis of 10-year survival. Cancer J Sci Am 3:6-12, 1997

82. Blichert-Toft $M$, Nielsen $M$, Düring $M$, et al: Long-term results of breast conserving surgery vs. mastectomy for early stage invasive breast cancer: 20-year follow-up of the Danish randomized DBCG82TM protocol. Acta Oncol 47:672-681, 2008

83. Fisher B, Anderson S, Bryant J, et al: Twentyyear follow-up of a randomized trial comparing total mastectomy, lumpectomy, and lumpectomy plus irradiation for the treatment of invasive breast cancer. N Engl J Med 347:1233-1241, 2002

84. Poggi MM, Danforth DN, Sciuto LC, et al: Eighteen-year results in the treatment of early breast carcinoma with mastectomy versus breast conservation therapy: The National Cancer Institute Randomized Trial. Cancer 98:697-702, 2003

85. van Dongen JA, Voogd AC, Fentiman IS, et al: Long-term results of a randomized trial comparing breast-conserving therapy with mastectomy: European Organization for Research and Treatment of Cancer 10801 trial. J Natl Cancer Inst 92:1143-1150, 2000

86. Veronesi $U$, Cascinelli $N$, Mariani $L$, et al: Twenty-year follow-up of a randomized study comparing breast-conserving surgery with radical mastectomy for early breast cancer. N Engl J Med 347:1227-1232, 2002

87. Gomez SL, Lichtensztajn D, Kurian AW, et al: Increasing mastectomy rates for early-stage breast cancer? Population-based trends from California. J Clin Oncol 28:e155-e157; author reply e158, 2010

88. Redd WH, Montgomery GH, DuHamel KN: Behavioral intervention for cancer treatment side effects. J Natl Cancer Inst 93:810-823, 2001

89. Cassidy JD, Carroll LJ, Côté P, et al: Effect of eliminating compensation for pain and suffering on the outcome of insurance claims for whiplash injury. N Engl J Med 342:1179-1186, 2000

90. Harris I, Mulford J, Solomon M, et al: Association between compensation status and outcome after surgery: A meta-analysis. JAMA 293:1644-1652, 2005

91. Ebrahim S, Malachowski C, Kamal El Din M, et al: Measures of patients' expectations about recovery: A systematic review. J Occup Rehabil 25: 240-255, 2015

92. Khan JS, Devereaux PJ, LeManach $Y$, et al: Patient coping and expectations about recovery predict the development of chronic post-surgical pain after traumatic tibial fracture repair. Br J Anaesth 117: 365-70, 2016

\section{Affiliations}

Li Wang, Yaping Chang, Samantha Craigie, Rachel J. Couban, Susan Reid, Michael McGillion, and Jason W. Busse, McMaster University, Hamilton; Sean A. Kennedy and Chris J. Hong, University of Toronto, Toronto; Brian Y. Hong, University of Ottawa, Ottawa, Ontario, Canada; Li Wang, West China Hospital, Sichuan University, Chengdu, People’s Republic of China; Henry Y. Kwon, Wayne State University School of Medicine, Detroit, MI; Beatriz Romerosa, University Hospital of Toledo, Toledo, Spain; James S. Khan, Stanford University, Palo Alto, CA; and Victoria Blinder, Memorial Sloan Kettering Cancer Center, New York, NY. 
Predictors of Unemployment After Breast Cancer Surgery: A Systematic Review and Meta-analysis of Observational Studies

The following represents disclosure information provided by authors of this manuscript. All relationships are considered compensated. Relationships are self-held unless noted. I = Immediate Family Member, Inst = My Institution. Relationships may not relate to the subject matter of this manuscript. For more information about ASCO's conflict of interest policy, please refer to www.asco.org/rwc or ascopubs.org/jco/site/ifc.

Li Wang

No relationship to disclose

Brian Y. Hong

No relationship to disclose

Sean A. Kennedy

No relationship to disclose

\section{Yaping Chang}

No relationship to disclose

Chris J. Hong

No relationship to disclose

Samantha Craigie

No relationship to disclose

Henry Y. Kwon

No relationship to disclose

\section{Beatriz Romerosa}

No relationship to disclose

Rachel J. Couban

No relationship to disclose

\section{Susan Reid}

No relationship to disclose

\section{James S. Khan}

No relationship to disclose

Michael McGillion

No relationship to disclose

\section{Victoria Blinder}

Consulting or Advisory Role: The Anthem Foundation, Pfizer

Jason W. Busse

No relationship to disclose 


\section{Acknowledgment}

We thank Reynard Bouknight, College of Human Medicine, Michigan State University; Aina Johnsson, Department of Social Work, Karolinska University Hospital Huddinge, Stockholm, Sweden; and Dorothee Noere, Medical Sociology Unit, Hannover Medical School, Hannover, Germany, for providing supplementary information or for answering our queries regarding their studies. No financial compensation was provided to any of these individuals. 